\title{
ANALISIS PERGUDANGAN DI BAGIAN GUDANG BARANG JADI (FINISHGOODS) PT NIPRESS TBK CILEUNGSI BOGOR
}

\author{
Nurmaliana Yusuf ${ }^{1)}$, Yevita Nuryanti ${ }^{2)}$ \\ ${ }^{1,2)}$ Program Studi Manajemen Logistik Industri Elektronika Politeknik APP Jakarta \\ *)Penulis korespondensi : lianurmaliana35@gmail.com
}

DOI Number : $\underline{10.30988 / j m i l . v 1 i 1.3}$

\begin{abstract}
This research was made aiming to determine the work processes in the warehouse of finished goods, which has a main activity that is in the process of receiving, storing and shipping goods, especially in the warehouse of finished. This research was conducted by analyzing the actual conditions are compared to a SOP (Standard Operating Procedure) and Work Instructions. An SOP (Standard Operating Procedure) is made and documented in writing containing procedure or workflow to be achieved by a company or institution. In addition to analyzing the main activities of the warehouse, ths research also analyzes the process palletize (roll battery), standard processes FIFO (First In First Out), and also the process of inventory taking which three are in the process of storage of finished goods. This analysis included descriptive comparative analysis by comparing the actual conditions in the finished goods warehouse with a procedure and work instructions. The results of this analysis is the process activity finished goods warehouse of the receipt, storage, inventory taking, and local delivery is not in accordance with the procedures and work instructions are there, but a standard process FIFO (First In First Out), and the process palletize (rolls battery) has been carried out in accordance with the procedures and work instructions finished goods warehouse.
\end{abstract}

Keywords: Warehousing, SOP (Standard Operating Procedures, Work Instructions, palletize, FIFO (First In First Out)

\begin{abstract}
Abstrak
Penelitian Penelitian ini dibuat bertujuan untuk mengetahui proses kerja pergudangan di gudang barang jadi, yang mempunyai aktivitas utama yaitu pada proses penerimaan, penyimpanan dan pengiriman barang. Penelitian ini dilakukan dengan cara menganalisis kondisi aktual yang dibandingkan dengan sebuah SOP(Standard Operational Prosedure) dan Instruksi kerja. Sebuah SOP(Standard Operational Prosedure) dibuat dan didokumentasikan secara tertulis yang memuat prosedure atau alur kerja yang ingin diraih oleh sebuah perusahaan ataupun instansi. Selain menganalisis aktivitas utama gudang, penelitian ini juga menganalisis proses palletize (gulung battery), proses standar FIFO(First In First Out), dan juga proses stock opname yang ketiganya termasuk pada bagian proses penyimpanan barang jadi. Analisis ini termasuk analisis deskriptif yang bersifat komparatif dengan membandingkan kondisi aktual di gudang barang jadi dengan sebuah prosedure dan instruksi kerja. Hasil yang didapat dari analisis ini adalah proses aktivitas gudang barang jadi dari proses penerimaan, penyimpanan, stock opname, dan pengiriman lokal belum sesuai dengan prosedure dan instruksi kerja yang ada, tetapi proses standar FIFO(First In First Out), dan proses palletize (gulung battery) sudah dilakukan sesuai dengan prosedure dan instruksi kerja gudang barang jadi.
\end{abstract}

Kata kunci: Pergudangan, SOP(Standard Operational Prosedure, Instruksi Kerja, Palletize, FIFO(First In First Out) 


\section{PENDAHULUAN}

Dalam suatu perusahaan besar, gudang mempunyai arti yang sangat penting untuk aliran barang dalam perusahaan tersebut. Gudang adalah sebuah bangunan atau ruangan yang digunakan sebagai tempat penyimpanan semua bahan di pabrik. Di dalam gudang terdapat tiga aktivitas utama yaitu proses penerimaan barang, proses penyimpanan barang, dan proses pendistribusian barang. Aktivitas di dalam gudang tersebut yang dinamakan dengan pergudangan. Fungsi utama gudang adalah tempat penyimpanan bahan-bahan mentah (raw material), barang setengah jadi (intermediate goods), maupun produk yang telah jadi (finish goods).

Gudang juga mempunyai peran penting guna mendukung keberhasilan perusahaan dalam mencapai tujuannya, hal tersebut harus didukung dengan aktivitas pergudangan yang baik, dimulai dari poses penerimaan barang, proses penyimpanan barang, perawatan barang, pencatatan persediaan, sampai dengan pengeluaran barang untuk dikirim kepada konsumen. Selain itu perlu juga ditunjang dengan adanya sistem informasi pergudangan, yang berfungsi untuk membantu pengelolaan barang-barang di dalam gudang. Dengan pengelolaan informasi yang teratur, diharapkan kegiatan yang berlangsung di dalam gudang dapat berjalan dengan baik.

Hal ini menyebabkan kebutuhan akan adanya gudang disuatu perusahaan sangat penting adanya. Seperti di PT. Nipress, Tbk., sebagai perusahaan yang bergerak dibidang manufakturing penghasil produk battery motor, mobil dan industrial, yang setiap departemen mempunyai cara kerja masingmasing tanpa terkecuali departemen warehouse. Departemen warehousePT. Nipress, Tbk.terbagi empat bagian yaitu gudang bahan baku, gudang barang setengah jadi, gudang pembantu dan gudang barang jadi (finish good). Pedoman kerja yang digunakan para pegawai warehouse dalam melakukan pekerjaannya adalah sebuah SOP (Standard Operational Procedure) atau sebuah lembar instruksi kerja.
Disalah satu gudang PT. Nipress. Tbk. yaitu bagian gudang barang jadi (finish goods) terdapat adanya beberapa masalah yang meliputi tiga aktivitas utama gudang yaitu proses penerimaan, penyimpanan, dan pengiriman. Pada proses penerimaan barang, terdapat masalah yang disebabkan karena kelalaian para pegawai yang salah dalam menginput barang jadi ke komputer, khususnya menginput FP Code yang menjadi acuan terhadap battery. Hal ini mengganggu pada proses pengecekan slip transfer yang masuk dengan hasil penginputan barang tersebut.

\section{METODE PENELITIAN}

Proses penerimaan barang jadi menjadi aktivitas awal dalam kegiatan utama gudang. Berikut ini adalah alur proses kerja kondisi actual penerimaan barang jadi dan uraian proses kerjanya sebagai berikut:

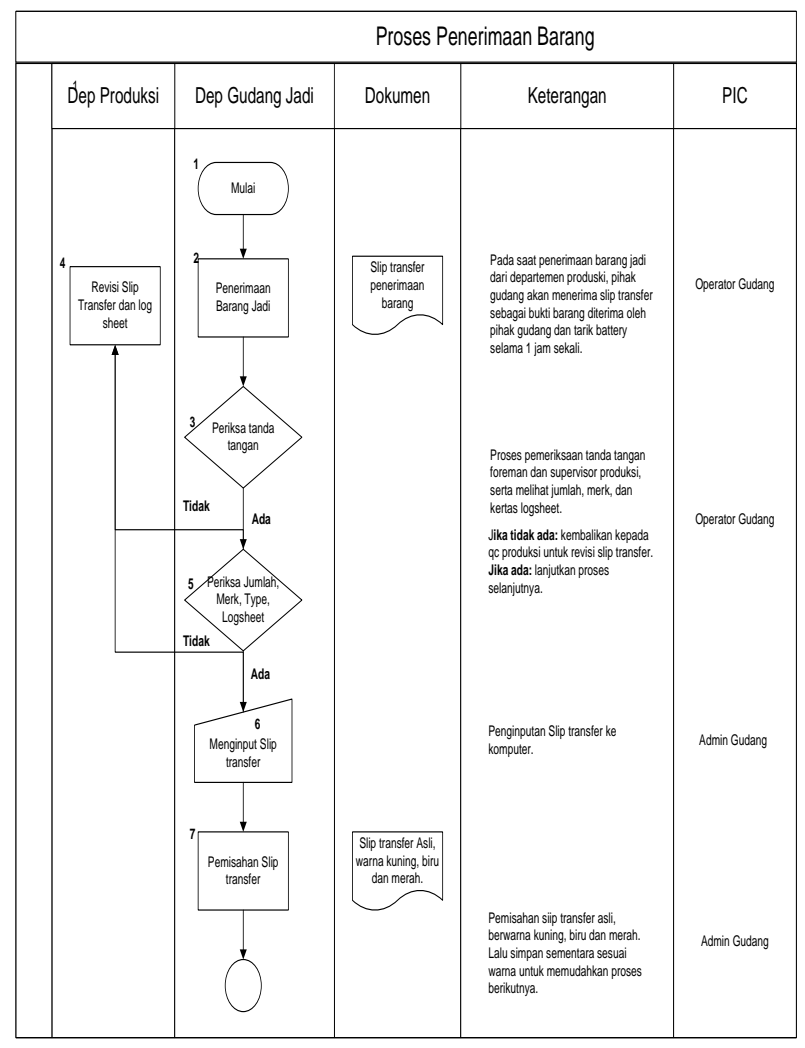

Gambar 1. Proses Penerimaan Barang 
Setelah proses penerimaan, Maka akan diteruskan kepada proses penyimpanan barang di gudang. Berikut ini adalah alur proses kerja kondisi actual penyimpanan barang jadi dan uraian proses kerjanya sebagai berikut:

$$
\begin{gathered}
\text { 1. Memberikan identitas barang } \\
\text { Pada proses ini operator }
\end{gathered}
$$
gudangmemberikan identitas barang (kartu koordinat) sesuai kode barang masuk. Dengan kata lain kartu ini sebagai pengenal battery yang akan disimpan. Kegiatan ini juga memudahkan para pegawai gudang dalam menemukan barang yang akan dikirim.

\section{Proses palletize}

Operator akan melakukan proses palletize (gulung battery) sebelum battery disimpan di rak penyimpanan. Fungsidari proses palletize untuk melindungi barang dari debu dan kotoran lainnya.

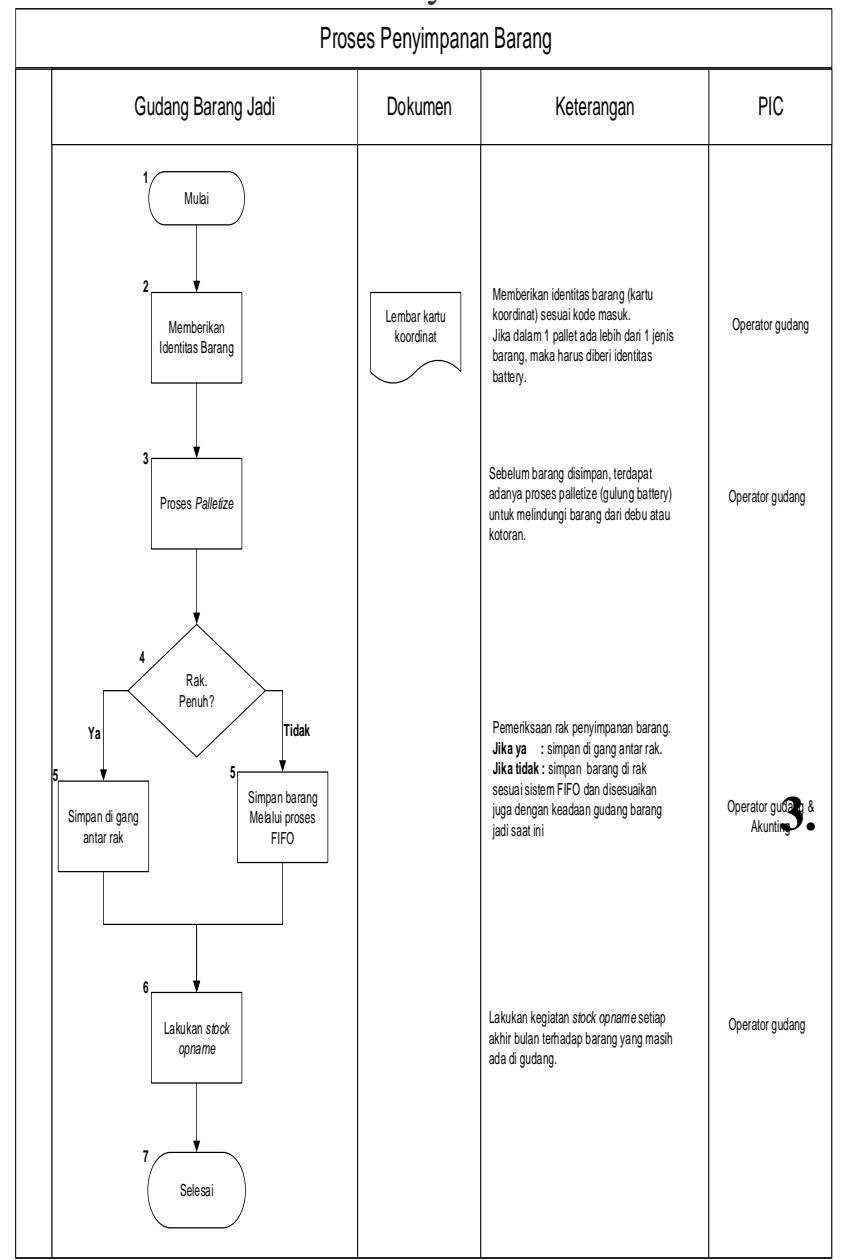

Gambar 2. Proses Penyimpanan Barang
Proses terakhir yaitu proses pengiriman barang kepada konsumen. Berikut ini adalah alur proses kerja kondisi aktual proses pengiriman local barang jadi dan uraian proses kerjanya sebagai berikut:

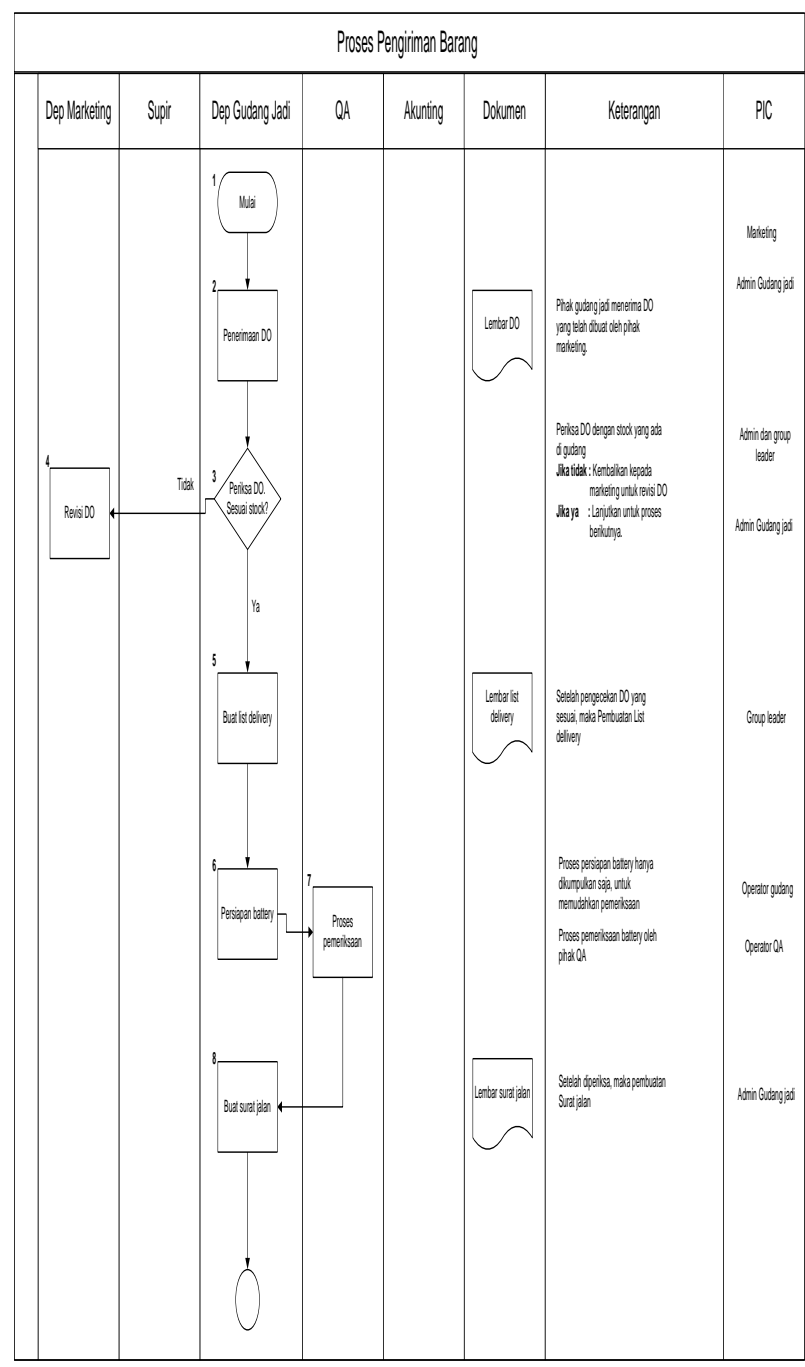

\section{HASIL DAN PEMBAHASAN}

\section{Proses Penerimaan}

Berikut ini adalah tabel perbandingan antara proses aktual penerimaan barang jadi dengan sebuah prosedure penerimaan, serta instruksi kerja penerimaan barang jadi yaitu:

1. Proses penerimaan barang

Di dalam prosedure penerimaan, insruksi kerja, maupun keadaan aktualnya proses menerima barang dan slip transfer dari 
departemen produksi, sudah sesuai dan telah dilakukan dengan baik dan benar.

2. Proses pemeriksaan slip transfer

Di dalam procedure penerimaan dijelaskan untuk memeriksa slip transfer dengan disesuaikan barang aktual, dalam instruksi kerja lebih proses pemeriksaan tersebut lebih dirinci denganjelas. Pada keadaan aktualnya kegiatan tersebut sudah sesuai dan telah dilakukan oleh pegawai gudang dengan baik dan benar.

3. Input data

Pada kondisi aktual proses input data ke computer sudah dilakukan sesuai dengan procedure penerimaan dan insruksi kerja yang ada. Tetapi terdapat masalah dalam menginput barang jadi ke komputer, khususnya menginput FP Code yang menjadi acuan terhadap battery. Sebaiknya pegawai gudang yang bertugas dalam input data yaitu admin gudang bias lebih telti dalam bekerja dan meningkatkan komunikasi antara pihak atasan dan bawahan, serta sebaiknya adakan sosialisasi kembali kepada pegawai mengenai pengenalan FP Code yang berjumlah 323 buah agar kesalahan dalam penginputan tidak terjadi kembali.

4. Catat battery di kartu koordinat

Pada proses catat battery di kartu koordinat tidak dijelaskan didalam prosedure penerimaan barang jadi. Tetapi proses ini hanya dijelaskan pada instruksi kerja saja dan tetap dijalankan oleh para pegawai gudang dengan benar dan sesuai.

\section{Simpan barang}

Proses terkahir adalah simpan barang di layout yang telah ditentukan. Pada kondisi aktualnya tidak dilakukan sesuai dengan instruksi kerja yang ada dikarenakan terdapat masalah akibat terjadi penumpukan barang digudang, yang menyebabkan layout yang sudah dibuat tidak digunakan dengan sempurna, dan terdapat adanya perubahan penyimpanan barang yang disesuaikan dengan keadaan barang dalam gudang. Sebaiknya dilakukan revisi ulang pembuatan layout gudang barang jadi yang disesuaikan dengan keadaan gudang barang jadi saat ini, karena rata-rata pegawai gudang jadi adalah pegawai baru. Selain itu sambil menunggu revisi gambar layout gudang barang jadi sebaiknya juga manajemen gudang dengan bagian atasan di perusahaan PT. Nipress, Tbk saling bekerjasama dan bermusyawarah mengenai solusi pemecahan masalah penumpukan barang tersebut.

\section{Proses Penyimpanan}

Berikut ini adalah perbandingan antara proses aktual penyimpanan barang jadi dengan sebuah prosedure penyimpana, serta instruksi kerja penyimpanan barang jadi yaitu:

\section{Proses penerimaan battery}

Pada prosedure penyimpanan hanya menjelaskan tentang simpan battery saja, tidak dijelaskan lagi untuk kegiatan lainnya. Tetapi di insruksi kerja proses penyimpanan barang lebih diperjelas. Kondisi aktual proses menerima battery dari departemen produksi sudah sesuai dan telah dilakukan dengan baik dan benar sesuai dengan instruksi kerja yang ada.

2. Pemberian identitas battery

Proses pemberian identitas battery telah sesuai dan telah dilakukan dengan baik dan benar mengikuti instruksi kerja yang ada di gudang.

\section{Simpan barang}

Pada prosedure penyimpanan barang, hanya disebutkan kegiatan simpan barang saja untuk kegiatan lainya tidak disebutkan. Maka dari itu untuk proses simpan barang tetap dilakukan, tetapi tidak sesuai dengan layout gudang barang jadi. Terdapat masalah akibat terjadi penumpukan barang digudang, yang menyebabkan layout yang sudah dibuat tidak digunakan dengan sempurna, dan terdapat adanya perubahan peyimpanan barang yang disesuaikan dengan keadaan barang dalam gudang. Sebaiknya 
dilakukan revisi ulang pembuatan layout gudang barang jadi yang disesuaikan dengan keadaan gudang barang jadi saat ini, karena rata-rata pegawai gudang jadi adalah pegawai baru.Selain itu sambil menunggu revisi gambar layout gudang barang jadi sebaiknya juga manajemen gudang dengan bagian atasan di perusahaan PT. Nipress, Tbk saling bekerjasama dan bermusyawarah mengenai solusi pemecahan masalah penumpukan barang tersebut.

\section{Memastikan pallet barang}

Pada kondisi aktual proses memastikan pallet barang dilakukan sesuai dengan instruksi kerja yang ada.

\section{Memastikan penempatan battery}

Pada proses memastikan penempatan layout yaitu jika battery penuh atau over kapasitas maka battery akan di tempatkan di gang antar rak dengan diberi identitas penempatan sementara, hal tersebut telah dilakukan dengan benar dan sesuai instruksi kerja. Tetapi terdapat masalah pada penempatan barang di gang antar rak yang berlebihan, menyebabkan ruangan menjadi sempit dan gerak alat bantu (forklift) yang mengangkut barang menjadi terhambat. Hal ini masih menjadi tugas yang sangat besar bagi perusahaan, karena semakin banyak barang yang menumpuk jika tidak ditangani. Sebaiknya perlu adanya kerjasama pihak manajemen gudang dengan bagian atasan di perusahaan PT. Nipress, Tbk mengenai solusi pemecahan masalah penumpukan barang tersebut. Selain itusupir forklift perlu berhatihati saat menyimpan ataupun mengeluarkan barang agar barang yang disimpan di gang antar rak tidak rusak akibat mesin forklift tersebut.

6. Pengecekan Voltase dan CCA

Proses pengecekkan voltase dan CCA terhadap battery tidak dilakukan sesuai dengan instruksi kerja. Karena hal tersebut dilakukan sebelum proses pengiriman.

7. Proses stock opname
Proses stock opname dilakukan sudah sesuai dengan intruksi kerja di gudang barang jadi. Tetapi terdapat masalah yaitu sebagian besar hasil stock opname berbeda dengan hasil penginputan yang dilakukan admin gudang. Sebaiknya pegawai gudang yang bertanggung jawab terhadap proses stock opname bisa lebih teliti dalam melakukan pengecekan, dan komunikasi tetap dijaga antar departemen agar tidak ada saling melempar tanggung jawab seperti yang terjadi saat ini terhadap hasil laporan stock opname.

\section{Proses Pengiriman}

Berikut ini adalah perbandingan antara proses aktual palletize (gulung battery) dengan instruksi kerja palletize (gulung battery) yaitu: 1. Menerima DO (Delivery Order)

Di dalam prosedure pengiriman, insruksi kerja, maupun keadaan aktualnya proses menerima DO (Delivery Order) dari pihak marketing, sudah sesuai dan telah dilakukan dengan baik dan benar, tetapi terdapat masalah yaitu bukti DO(Delivery Order) telat datang. Seharusnya DO (Delivery Order) dikirim ke pegawai bagian gudang barang jadi, yaitu 2 (dua) hari sebelum proses pengiriman. Tetapi kenyataannya DO (Delivery Order) datang dari pihak marketing support pada saat barang seharusnya dikirim kepada konsumen.Sebaiknya perlu adanya ketegasan dari pihak gudang barang jadi mengenai kesepakatan yang telah dibuatbersama, hal ini membantu agar lebih memudahkan dan memperlancar proses pengiriman barang dan komunikasi juga perlu ditingkatkan agar masalah ini tidak terus berlanjut untuk kedepannya.

2. Pengecekkan DO (Delivery Order) Walaupun proses pengecekkan DO (Delivery Order) dengan stock yang ada di gudang tidak disebutkan di prosedure pengiriman, tetapi pada kondisi aktualnya proses ini dijalankan sesuai dengan instruksi kerja pengiriman lokal barang jadi

3. Pembuatan list delivery

Di dalam prosedure pengiriman, insruksi kerja, maupun keadaan aktualnya proses pembuatan list delivery sudah sesuai dan telah 
dilakukan dengan baik dan benar oleh pegawai gudang.

4. Proses persiapan battery untuk pengiriman

Pada kondisi aktual persiapan battery untuk pengiriman ke area cargo ready tidak dilakukan sesuai dengan instruksi kerja. Karena area cargo ready di dalam gudang, saat ini tidak dilakukan kembali karena sudah dipakai untuk tempat penyimpanan barang jadi, lalu dilanjutkan dengan proses pemeriksaan battery sesuai list delivery tetap dilakukan dan melakukan loading barang ke mobil. Sebaiknya perlu adanya revisi pada lembar instruksi kerja, untuk memudahkan pegawai dalam memahami instruksi kerja tersebut. dalam melakukan pekerjaannya.

5. Pembuatan surat jalan

Di dalam prosedure pengiriman, insruksi kerja, maupun keadaan aktualnya proses pembuatan surat jalan, sudah sesuai dan telah dilakukan dengan baik dan benar oleh pegawai.

6. Proses packing standar battery

Walaupun proses packing standar untuk battery curah tidak disebutkan di prosedure pengiriman, tetapi pada kondisi aktualnya proses ini sudah sesuai dan telah dilakukan dengan baik dan benar sesuai dengan instruksi kerja pengiriman barang.

\section{Proses stuffing}

Pada prosedure pengiriman dijelaskan untuk melakukan proses cross check sesuai surat jalan, tetapi di instruksi kerja lebih dijelaskan proses cross check yang dimaksud adalah proses stuffing atau bisa disebut pengecekan sebelum dikirim kepada konsumen dan hal ini dilakukan verifikasi oleh pihak bagain gudang dan GA. Kondisi aktual terhadap proses ini telah dilaksanakan oleh pegawai gudang sesuai dengan instruksi kerja yang ada.

8. Pendistribusian surat jalan

Pada prosedure pengiriman barang disebutkan setelah proses cross check maka surat jalan akan didistribusikan langsung kepada supir untuk dibawa saat pengiriman, tetapi di instruksi kerja lebih di perjelas lagi, yaitu surat jalan yang telah disetujui akan ditanda tangani dan sebelum diberikan kepada customermaka warna kuning dan biru dilepas (warna biru untuk accounting, dan warna kuning untuk file di gudang). Kondisi aktual yang terjadi sudah sesuai dengan instruksi dan prosedure yang ada.

9. Input data

Di dalam prosedure pengiriman, insruksi kerja, maupun keadaan aktualnya prosesinput data barang yang keluar gudang, sudah sesuai dan telah dilakukan dengan baik dan benar oleh pegawai gudang.

10. Serah terima barang kepada customer Walaupun proses serah terima battery kepada customer tidak disebutkan di prosedure pengiriman, tetapi pada kondisi aktualnya proses ini telah dilakukan dengan baik dan benar sesuai dengan instruksi kerja pengiriman barang.

11. Pengembalian surat jalan

Pada prosedure pengiriman barang disebutkan bahwa supir akan mengembalikan surat jalan asli kepada admin gudang dan mendistribusikan kepada pihak finance. Tetapi di instruksi kerja admin gudang akan melakukan pendistribusian kepada pihak accounting. Kondisi aktual yang terjadi adalah keduanya dijalankan karena surat jalan warna biru ada 2 (dua) lembar yaitu ada yg diberikan kepada bagian finance dan accounting. Sebaiknya pada saat pembuatan prosedure ataupun instruksi kerja, kedua kalimat tersebut harus saling berkesinambungan. Untuk memudahkan pegawai dalam memahami kedua arti dari keduanya.

\section{KESIMPULAN}

1. Proses penerimaan barang jadi

Pada kondisi aktual proses penerimaan belum sesuai dengan prosedure penerimaan dan instruksi kerja penerimaan gudang barang jadi, dikarenakan terdapat 1 (satu) proses yang tidak sesuai, yaitu pada proses penyimpanan yang tidak sesuai layout gudang, dan terdapat masalah pada proses input data ke komputer.

2. Proses penyimpanan barang jadi Pada kondisi aktual proses penerimaan belum sesuai dengan prosedure penerimaan dan instruksi kerja penerimaan gudang barang jadi, dikarenakan terdapat 2 (dua) proses yang tidak sesuai, yaitu pada proses penyimpanan yang tidak sesuai layout dan proses 
pengecekkan Voltase dan CCA yang tidak dilakukan kembali. Proses yang lainnya sudah dilakukan sesuai dengan prosedure dan instruksi kerja namun terdapat masalah pada penempatan barang di gang antar rak dan proses stock opname.

3. Proses pengiriman lokal barang jadi Pada kondisi aktual proses pengiriman local belum sesuai dengan procedure pengiriman dan instruksi kerja pengiriman local gudang barang jadi, dikarenakan terdapat 1 (satu) proses yang tidak sesuai, yaitu pada proses persiapan battery di area cargo ready, dan terdapat masalah pada proses penerimaan lembar DO (Delivery Order) yang dikirim dari marketing ke gudang barang jadi.

\section{DAFTAR PUSTAKA}

Ahmad Shabah AMD, Imran. 2013. Analisis Proses Pergudangan di PT Keretaapi Indonesia UPT Balai Yasa Manggarai.Tugas akhir Akademi Pimpinan Perusahaan. Hal 5.

Ali, Muhamad MT-Purwanto, M.M. 2008. Teknik dan Manajemen Pergudangan.Jakarta: Direktorat pembinaan Sekolah Menengah Kejuruan. Hal 1.

Assauri, Sofjan. 2008. Manajemen Produksi dan Operasi. Jakarta: Lembaga penerbit Fakultas Ekonomi Universitas Indonesia. Hal 119

Eko aninindiyo, Firman ardiansyah-yaumala gitawedana. 2012. Perencanaan Tata Letak Gudang Menggunakan Metode Shared Storage di Pabrik Plastik Kota Semarang. Dinamika teknik.Hal 50.

Ginanjar M, Didan. 2008. Analisis Manajemen Logistik Dalam Menunjang Kelancaran Penjualan Spare Part Pada PD Orbit Moto Sport. Skripsi Universitas Widyatama. Hal 9.
Kurniawan S, Henry. 2013. Studi Deskriptif Manajemen Kualitas Dengan Metode 5S di Gudang Hypermarket X Surabaya. Calyptra: Jurnal ilmiah Universitas Surabaya vol.2 No.2.Hal 2.

Manullang, M. 2008. Dasar-Dasar Manajemen.Yogyakarta: Universitas Gajah Mada. Hal 5.

Meilani, Difana dan Miftahuddin. 2010. Perancangan system informasi manajemen persediaan di Pdam Tirta Sakti Kab Kerinci. Junal Ilmiah Teknik Industri Teknik Industri Universitas Andalas. Hal 1.

Paluningtyas, Retno. 2014. Analisis Sistem Penyimpanan Obat di Gudang Farmasi Rumah Sakit Mulya Tangerang. Skripsi UIN Syarief Hidayatulloh Jakarta.Hal 38.

Sailendra, Annie. 2015. Langkah-Langkah PraktisMembuat SOP. Jogjakarta: Trans Idea Publishing. Hal 72. 